\title{
VITAMIN B12 LEVELS AND RELATIONSHIP BETWEEN B12 AND FASTING INSULIN LEVELS ELDERLY PATIENTS WITH METABOLIC SYNDROME
}

\author{
Fulden Sarac ${ }^{1}$, Sumru Savas ${ }^{1}$, Sefa Sarac $^{2}$, Fehmi Akcicek $^{1}$
}

${ }^{1}$ Department of Internal Medicine, Geriatrics Section, Ege University Medical Faculty/ Izmir/ TURKEY 2Department of Cardiology, Katip Celebi University, Atatürk Training and Research Hospital/ Izmir/ TURKEY

\section{OBJECTIVES}

Biochemical and clinical vitamin B12 deficiency has been demonstrated to be highly prevalent among patients with diabetes mellitus.

The aims of the study were 1 . to compare the vitamin B12 (VB12) levels, and 2. to investigate the relationship between VB12, fasting insulin and homeostasis model assessment (HOMA-IR) levels in elderly patients with metabolic syndrome (MetS).

\section{METHODS}

Study population included 121 (mean age $64.3 \pm 14.1 \mathrm{yrs})(80$ female, 41 male) elderly patients.

Patients were evaluated for MetS by Adult Treatment Panel III (ATPIII). Data such as VB12, insulin and other tests were retrospectively searched.

Vitamin B12 deficiency was defined as B12 concentrations $<197$ $\mathrm{pg} / \mathrm{ml}$.

\section{RESULTS}

Metabolic syndrome was diagnosed in 39 elderly patients (\%32.2).

The prevalence of low VB12 was $45.8 \%$ in elderly with MS.

Serum VB12 levels were significantly lower among patients aged $\geq 70$ years $(\mathrm{P}<.05)$.

In elderly patients with MetS, mean levels of VB12, fasting insulin and HOMA were found to be $370.1 \pm 58.6 \mathrm{pg} / \mathrm{ml}$, $13.4 \pm 1.1 \mu \mathrm{U} / 1,3.0 \pm 0.1$, respectively.

However, mean levels of VB12, fasting insulin and HOMA were found to be $383.9 \pm 66.0 \mathrm{pg} / \mathrm{ml}, 8.4 \pm 2.7 \mu \mathrm{U} / 1,2.71 \pm 0.9$, in the other elderly patients, $(p=0.90),(p=0.70),(p=0.003)$, respectively.

Mean levels of VB12 were negatively correlated with fasting insulin levels $(r=-0.800, p=0.01)$ in elderly with MetS.

\section{CONCLUSIONS}

Mean levels of VB12 were not different in elderly patients with or without MetS, but negatively correlated with fasting insulin in elderly with MetS. 